\title{
ORAL LACTOFERRIN PROPHYLAXIS TO PREVENT SEPSIS AND NECROTISING ENTEROCOLITIS OF VERY LOW BIRTH WEIGHT NEONATES IN NEONATAL INTENSIVE CARE UNIT AND EFFECT ON T-REGULATORY CELLS
}

\author{
I. Mungan Akin ${ }^{1}$, B. Atasay ${ }^{1}$, F. Dogu ${ }^{2}$, E. Okulu ${ }^{1}$, S. Arsan ${ }^{3}$, H.D. Karatas ${ }^{1}$, S. Alan ${ }^{3}$, A. Kıllıç ${ }^{1}$, A. \\ Ikinciogullari $^{1}, \mathrm{~T}$. Turmen ${ }^{1}$ \\ ${ }^{1}$ Ankara University, ${ }^{2}$ Ankara University, Faculty of Medicine, ${ }^{3}$ Neonatology, Ankara University, Faculty of \\ Medicine, Ankara, Turkey
}

Aim of the study is to evaluate whether oral administration of lactoferrin (LF) can enhance host defense and reduce late onset sepsis and NEC in VLBW infants, and to determine its effect on regulatory-T cells. The study was designed as a prospective, placebo-controlled, randomized trial in VLBW infants, who were randomly assigned to receive orally either $200 \mathrm{mg} \mathrm{LF}(\mathrm{n}=25)$ or placebo $(\mathrm{n}=25)$ daily. Episodes of suspected and culture proven late onset sepsis and NEC were recorded. CD4+25+ FOXP3+ lymphocytes were determined by flow cytometry at birth and discharge. Prenatal, natal and postnatal characteristics of the groups were similar. Mean gestational ages of groups were $30,3 \pm 2,5$ and 29,5 $\pm 1,6$ weeks, and birth weights were $1307 \pm 262,1 \mathrm{~g}$ and $1290 \pm 346,7 \mathrm{~g}$, respectively. During hospitalization period 14 vs 4 culture proven sepsis were observed in control and study group, respectively $(p<0,05)$. In group 2 , none of the patients experienced grade 2 and 3 NEC, while 5 babies from Group $1(p>0,05)$. Regulatory-T cell levels at birth and at discharge were similar in two groups. The increase in FOXP3 expression at discharge was significantly higher in oral LF group $(p<0,05)$.In this study, oral LF significantly lowered culture proven sepsis rate. Similar effect was observed in NEC rate but without statistical significance. The treated group took shorter time to reach full enteral feedings and no adverse effect was observed. The significant higher increase in FOXP3 expression in the LF group can be the mechanism for protective effects of LF on late onset sepsis and NEC. 